\title{
The Quantitative risk Analysis for Oil Tank Storage Areas Considering Different Firefighting Ability
}

\author{
J.L.Zhao, H.Huang*, B.N.Su, N.Zhang \& M.Fu \\ Institute of Public Safety Research, Department of Engineering Physics, Tsinghua University, Beijing, China
}

\begin{abstract}
With the enlargement of the urban areas, the threats of the oil storage tank areas to the citizens are increasing. From the historical tank accident data, most oil tank accidents are associated with the domino effect, and an effective and fast rescue can give a good control of the accident spread. In this paper, the quantitative risk for oil tank storage areas under different firefighting ability is studied. The firefighting ability is represented by the firefighting starting time. The domino effect is considered in detail and the heat flux contribution of the tank area is obtained using the solid flame model. According to the risk distribution, the best rescue positions can be determined by the firefighters. Moreover, the effects of the tank volume and the thermal radiation on the tank failure are discussed. This method is applied to the risk analysis of a real storage tank area. The results can provide some guidance on the planning of the fire station and the firefighting foam preparation.
\end{abstract}

KEYWORD: tank areas; domino effect; firefighting starting time; risk distribution

\section{INTRODUCTION}

Along with the rapid process of industrialization and urbanization in China, many storage tank areas are surrounded by dense clusters of neighborhoods where population densities are very high (Khan et al., 1998). Because the number of tanks and the volumes are increasing fast for most tank storage areas, the influence between the tanks has become quite obvious. Most severe tank accidents are related to the domino effects from the statistical data of tank fires (Persson et al., 2004). Therefore it is necessary to quantitatively evaluate the risk of storage tank areas considering the domino effects for urban planning.

Several studies have proposed the procedures in the quantitative assessment of domino events (Faisal I. Khan, S. A. Abbasi, 1988; Cozzani et al, 2005). The equipment failure probability models and threshold values for equipment failure were developed (Cozzani et al, 2005). Using the probability model, the failure probability of tanks caused by the hazardous factors (radiation, overpressure, fragments) can be evaluated. The firefighting starting time plays an important role on the control of the accident escalation. In this study, the firefighting starting time is decided by the emergency response time and the emergency preparation time especially for the preparation of the low-expansion foam. The risk distributions under different firefighting starting time are presented.

\section{METHOD}

\subsection{Identification of basic events}

The severe accidents initially originate from some basic events which are usually related with mere one storage tank. In this study, the basic events refer to the initial accidents that have threat to the surrounding tanks and persons. From the 100 domino accidents, Cozzani has summarized the initial events and harmful factors for storage tank areas (Cozzani et al, 2005). The pool fire as the basic events accounts for $44 \%$ as shown in Table 1.

Table 1 . The primary event and the harmful factors of the 100 domino accidents

\begin{tabular}{|c|c|c|c|c|}
\hline \multirow{2}{*}{$\begin{array}{c}\text { Primary } \\
\text { event }\end{array}$} & \multirow{2}{*}{ Number } & \multicolumn{3}{|c|}{ Harmful factors } \\
\cline { 3 - 5 } & & Radiation & Overpressure & Fragments \\
\hline VCE & 17 & 0 & 16 & 1 \\
\hline $\begin{array}{c}\text { Mechanical } \\
\text { explosion }\end{array}$ & 17 & 0 & 10 & 7 \\
\hline BLEVE & 13 & 0 & 0 & 13 \\
\hline Fireball & 1 & 1 & 0 & 0 \\
\hline Jet fire & 8 & 8 & 0 & 0 \\
\hline Pool fire & 44 & 44 & 0 & 0 \\
\hline
\end{tabular}


In the study, the atmospheric storage tanks are the main objects. So the pool fire is the main consideration. The full surface tank fire is regarded as the primary event.

\subsection{Pool fire model}

Of all the accidents in the storage tank areas, pool fire is the most common one (Munoz et al, 2007). The solid model is often used to estimate the thermal radiation from the pool fire. Further details about the pool fires models are discussed in SFPE (Nolan D P, 2010). The heat flux q can be calculated as follow:

$q=E F_{12} \tau$

where $\mathrm{E}=$ average emissive power at flame surface, $\mathrm{KW} / \mathrm{m}^{2} ; \mathrm{F}_{12}=$ the view factor; and $\tau=$ atmospheric transmissivity.

Using the pool fire model, the heat flux of storage tank areas can be obtained when some events happen.

\subsection{Domino effect model}

The tank failure probability is associated with the heat flux, tanks properties and the rescue abilities. A simple model considering the time to rescue is represented to express the probability of escalation (Landucci, 2009).

$$
P_{r}=a+b \times \ln (\mathrm{ttf})
$$

where $\operatorname{Pr}=$ probit variable, $\mathrm{ttf}=$ the time to failure without any mitigation action. The parameter $a$ and $b$ are decided by the maximum time required to start the emergency operations (tte1) and the maximum time required to start the mitigation actions (tte2).

$$
\begin{aligned}
& \ln (\mathrm{ttf})=-1.128 \ln (\mathrm{q})-2.667 \times 10^{-5} V+9887 \\
& a=\frac{3.718 \log (\text { tte } 1)-6.283 \log (\text { tte } 2)}{\log (\text { tte } 1)-\log (\text { tte } 2)} \\
& b=\frac{2.565}{\log (\text { tte } 1)-\log (\text { tte } 2)}
\end{aligned}
$$

The probability of tank failure is expressed as:

$$
P_{12}=\frac{1}{\sigma \sqrt{2 \pi}} \int_{-\infty}^{P_{r}-5} e^{-u^{2} / 2} d u
$$

where $\mathrm{P}_{12}=$ the probability of the tank failure.

In the paper, tte 1 is the time that the fire to be detected, the alarm to be given and the firefighting system of storage tank areas to be started. Usually, the tte 1 is set to be 5 minutes. The tte 2 is the firefighting started time that the mitigation action to be started including the foam preparation time, fire brigade arriving time etc.

In general, the arriving time that the fire brigades take is relative fixed and the tte 2 is mainly decided by the foam preparation time. The total prepared foam should ensure the enough supply intensity and supply time which is determined by the follows:

According to the "Code of design for low expansion foam extinguishing system" of China, the total amount of the low-expansion foam is:

$$
V=V_{1}+V_{2}
$$

where $V_{1}=$ effective dosage that injects into the accident tank; $V_{2}=$ useless dosage that fly off the outside accident tank.

The effective dosage is determined by the pool fire surface, effective discharge time and foam supply capacity.

$$
\mathrm{V}_{1}=\frac{\pi \mathrm{D}^{2}}{4} \times \mathrm{Q} \times \mathrm{t}
$$

where $\mathrm{D}=$ diameter of the pool fires, $\mathrm{m}$; $\mathrm{Q}=$ required foam supply capacity that the standard has regulated, $\mathrm{L} /\left(\mathrm{m}^{2} . \mathrm{min}\right)$; and $\mathrm{t}=$ fire-extinguishing time under the adequate foam supply, min.

The "Code of design for low expansion foam extinguishing system" of China has given out the foam supply duration which is usually considered as the fire-extinguishing time(tte $2=30 \mathrm{~min})$. In this paper, the fire-extinguishing time can be gained from the historical data of the cases (Persson et al, 2004). The present study summarizes the 42 fire accidents that had been extinguished in the past and have clear records on the fire-extinguishing time (as shown in the Table2).

The fire-extinguishing time can be set by the fire fighters according to emergency plans and real situation.

Table 2. Statistics of the tank fires extinguish time

\begin{tabular}{|c|c|c|c|}
\hline $\begin{array}{c}\text { Interval } \\
\text { number }\end{array}$ & time interval & $\begin{array}{c}\text { frequency } \\
\text { number }\end{array}$ & frequency \\
\hline 1 & $0<\mathrm{tte} 2 \leq 40$ & 15 & 0.357 \\
\hline 2 & $40<\mathrm{tte} 2 \leq 80$ & 14 & 0.333 \\
\hline 3 & $80<\mathrm{tte} 2 \leq 160$ & 5 & 0.119 \\
\hline 4 & $160<\mathrm{tte} 2 \leq 260$ & 6 & 0.143 \\
\hline 5 & $260<\mathrm{tte} 2 \leq 340$ & 1 & 0.024 \\
\hline 6 & $\mathrm{tte} 2 \geq 340$ & 1 & 0.024 \\
\hline
\end{tabular}

According to the low-expansion foam consumption and the location of the fire stations, the effective rescue time can be set properly by the decision makers.

\subsection{Personal risk analyses}

The probable model has been used by some authors and equation is as follow (Cozzani et al, 2005):

$$
\mathrm{Y}=-14.9+2.56 \ln \left(6 \times 10^{-3} q^{1.33} \times t_{e}\right)
$$


where $\mathrm{Y}=$ probit unit, $\mathrm{t}_{\mathrm{e}}=$ exposure time $(\mathrm{min}), \mathrm{q}$ is the heat flux $\left(\mathrm{W} / \mathrm{m}^{2}\right)$.

The personal risk equation is used:

$R=\frac{1}{\sigma \sqrt{2 \pi}} \int_{-\infty}^{Y-5} e^{-u^{2} / 2} d u$

where $\mathrm{R}=$ probability of death $(0 \leq \mathrm{R} \leq 1)$; and $\mathrm{u}=$ variable of integration.

\section{RESULTS AND DISCUSSION}

\subsection{The tank failure probability under the thermal radiation}

The failure of tanks is gradually increasing with continuous suffering from the thermal radiation. In order to quantitatively express the domino effect, the probability of tank failure under the different firefighting starting time is investigated. Meanwhile, the effects of the tank volume and the thermal radiation on the tank failure are discussed.

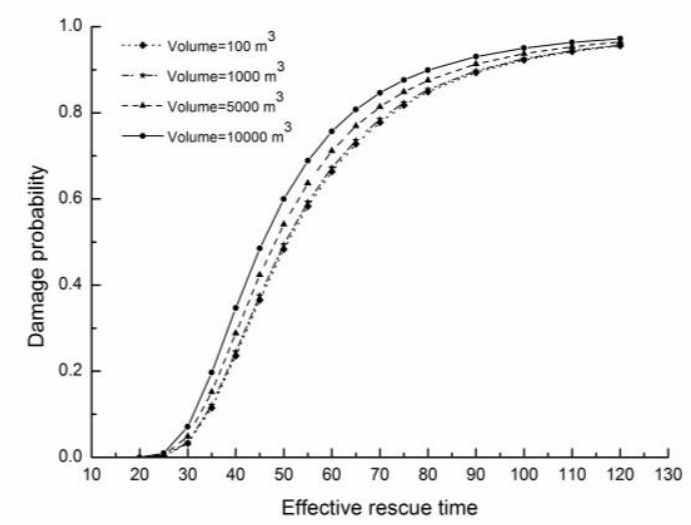

Figure 1. The different volume tank of damage probability variation with the tte 2

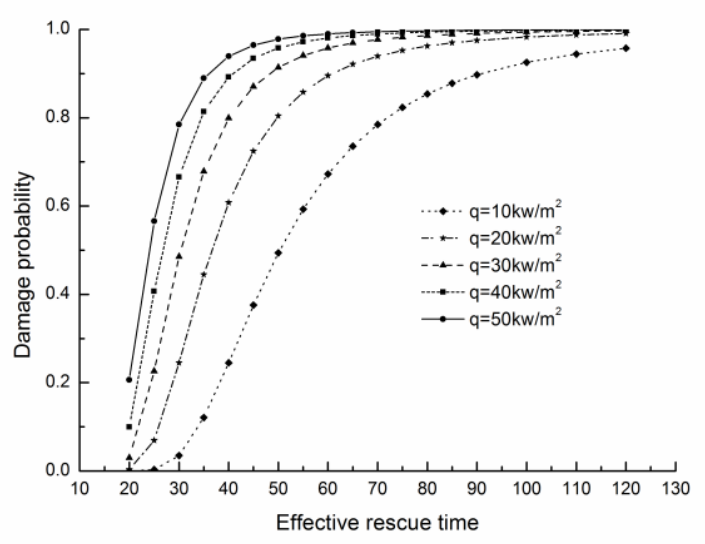

Figure 2. The tank damage probability variation with the tte2

From the result, the tank failure probability increases rapidly as the effective rescue time increases and the effective rescue time should be less than 20 minutes. From the Fig. 1, the tank volume is not a key influence factor in the tank failure model. The $100 \mathrm{~m}^{3}$ tank responses very similar to that of $10000 \mathrm{~m}^{3}$ under the same thermal radiation. From the
Fig.2, there is a big difference on the tank failure probability with the different thermal radiation and the tank failure is very sensitive to the thermal radiation. So the distance between the tanks should be considered when designs the layout of storage tank areas.

\subsection{Case study}

The chemical industrial park of Zhenhai which is located at Ningbo, Zhejiang province is selected as the object of this study. In order to calculate the risk conveniently, the storage tank area is divided into $20 \mathrm{~m} \times 20 \mathrm{~m}$ grids.

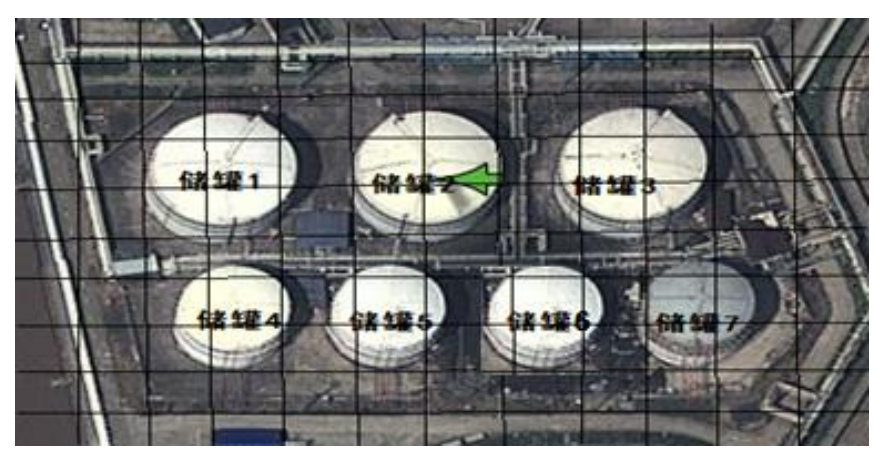

Figure 3. The tanks distribution of the storage tank areas

Firefighting starting time is an important factor in the disaster rescue. According to the practical situations, the tte 2 may be changed. The procedure is developed to calculate the risk values. In this case, Tank 2 is involved in the pool fire and different firefighting starting time (tte2) is discussed. Fig 4 shows the risk distribution of the storage tank area.

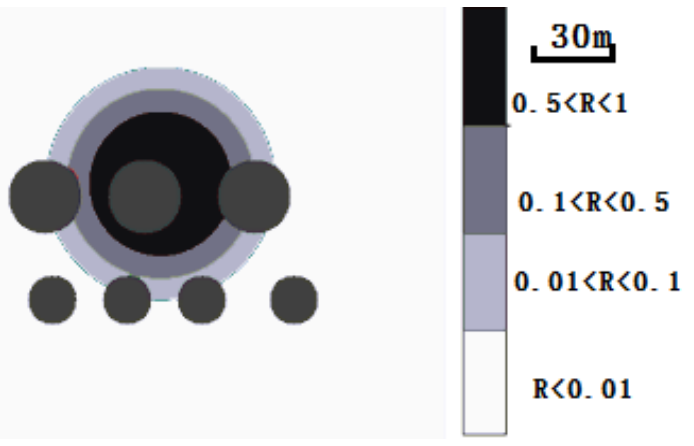

(a) tte2=20min

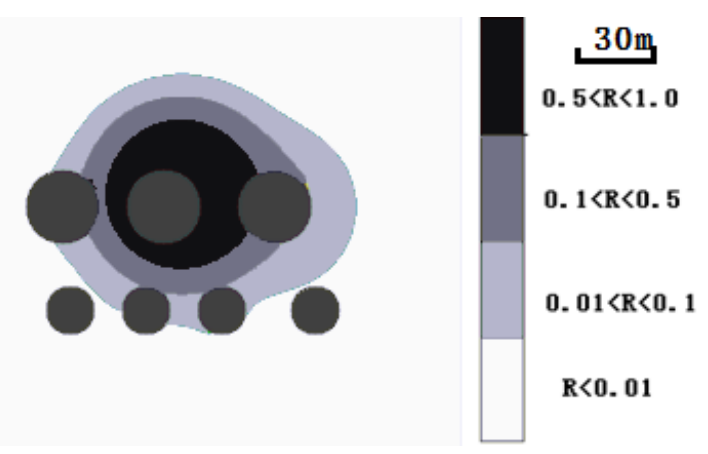

(b) tte $2=40 \mathrm{~min}$ 


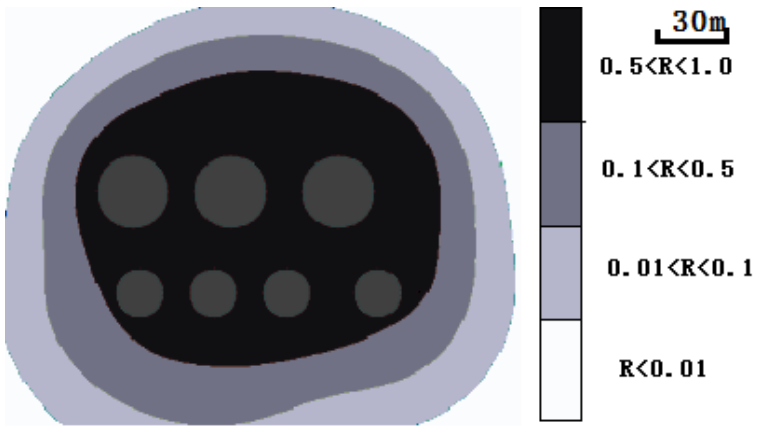

(c) tte $2=80 \mathrm{~min}$

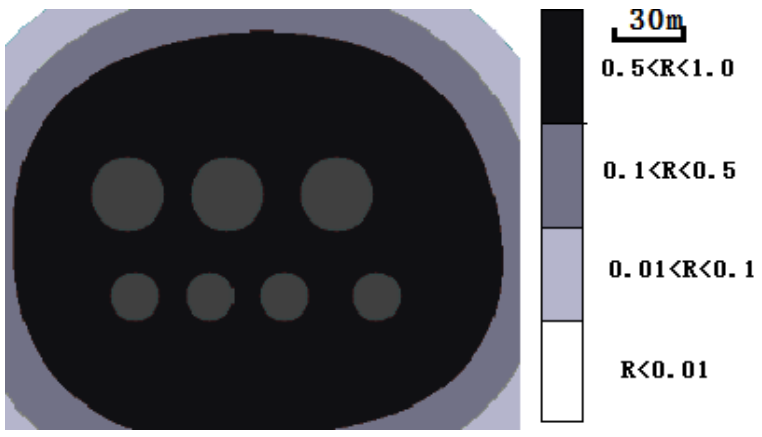

(d) tte $2=160 \mathrm{~min}$

Figure 4. The individual mortality risk distribution of the storage tank areas

In the maps, the circular regions represent the location of tanks and the other different colors shows the different individual mortality risk. From the variation of risk, the tte 2 has a great influence on the firefighting. When the pool fire happens, the environment conditions determined the best rescue positions firstly. With the continuous development of disasters, the domino effect gradually becomes obvious and has become one of the main consideration factors (shown Table 3). The high-risk (mortality risk $>0.5$ ) areas have enlarged more than 1 time when the tte 2 approaches $80 \mathrm{~min}$. So setting the fire station and emergency resources properly have positive effects on the individual mortality risk.

Table 3. The tank damage probability under the thermal radiation

\begin{tabular}{|c|c|c|c|c|c|c|}
\hline \multirow{2}{*}{$\begin{array}{c}\text { tte2 } \\
\text { (min) }\end{array}$} & \multicolumn{6}{|c|}{ Tank number } \\
\cline { 2 - 7 } & $\begin{array}{c}\text { Tank } \\
1\end{array}$ & $\begin{array}{c}\text { Tank } \\
3\end{array}$ & $\begin{array}{c}\text { Tank } \\
4\end{array}$ & $\begin{array}{c}\text { Tank } \\
5\end{array}$ & $\begin{array}{c}\text { Tank } \\
6\end{array}$ & $\begin{array}{c}\text { Tank } \\
7\end{array}$ \\
\hline 20 & 0 & 0 & 0 & 0 & 0 & 0 \\
\hline 40 & $0.77 \%$ & $5.31 \%$ & $0.96 \%$ & $0.66 \%$ & $0.78 \%$ & $0.08 \%$ \\
\hline 80 & $40.2 \%$ & $64.0 \%$ & $22.5 \%$ & $38.6 \%$ & $40.2 \%$ & $21.0 \%$ \\
\hline 160 & $85.5 \%$ & $93.9 \%$ & $74.2 \%$ & $84.7 \%$ & $85.5 \%$ & $73.0 \%$ \\
\hline
\end{tabular}

\section{CONCLUSIONS}

(1) The domino effect is obvious in the storage tank areas and should be considered into the designs. Moreover, based on the domino model, the dynamic risk values with the different firefighting ability are calculated. The best rescue positions can be determined based on the risk distribution which is very useful for the firefighters.

(2) In the accident situation, the method can compute the demand of the low-expansion foam. Some reference can be given for estimating the firefighting starting time.

(3)From the parameter analysis, the tank damage probability is very sensitive to the firefighting starting time which should be less than $20 \mathrm{~min}$. This method can provide some suggestions on the layout of the fire stations and the required amount of the low-expansion foam.

\section{ACKNOWLEDGMENTS}

This work was supported by the Ministry of Science and Technology of the People's Republic of China under Grant No. 2012BAK03B03 and Tsinghua University Self Research Program No. 2012 THZ0124.

\section{REFERENCES}

[1] Khan, Faisal I., and S. A. Abbasi. 1998. "Techniques and methodologies for risk analysis in chemical process industries." Journal of Loss Prevention in the Process Industries 11(4), 261-277.

[2] Persson, Henry, and Anders Lonnermark. 2004. "Tank Fires Review of fire incidents 1951-2003." SP RAPPORTSTATENS PROVNINGSANSTALT.

[3] Faisal I. Khan and S. A. Abbasi. 1998. Models for Domino Effect Analysis in Chemical Process Industries. Process Safety Progress, 17(2), 107-123.

[4] Cozzani, Valerio, et al. 2005. "The assessment of risk caused by domino effect in quantitative area risk analysis." Journal of Hazardous Materials 127 (1), 14-30.

[5] Munoz, M., Planas, E., Ferrero, F., \& Casal, J. 2007. Predicting the emissive power of hydrocarbon pool fires. Journal of hazardous materials, 144(3), 725-729.

[6] Nolan D P. Handbook of fire and explosion protection engineering principles: For oil, gas, chemical and related facilities. 2010. William Andrew.

[7] Landucci, Gabriele, et al. 2009. "The assessment of the damage probability of storage tanks in domino events triggered by fire." Accident Analysis \& Prevention 41(6), 1206-1215. 